\title{
CHILDHOOD OCULAR MORBIDITY IN KUMAON REGION- A TERTIARY HOSPITAL STUDY
}

\author{
Anshika Kashyap1, Shanti Pandey22, Govind Singh Titiyal ${ }^{3}$ \\ 1 Postgraduate Student, Department of Ophthalmology, Government Medical College, Haldwani. \\ ${ }^{2}$ Associate Professor, Department of Ophthalmology, Government Medical College, Haldwani. \\ 3Professor, Department of Ophthalmology, Government Medical College, Haldwani.
}

\section{ABSTRACT}

\section{BACKGROUND}

India has the largest blind population, more than any other country in the world. Among the total disability population of India, disability in seeing accounts for $18.8 \%$. A total population of 5 million people have disability in seeing, of which 1.1 million are between the age group 5 - 19 years. Eye diseases in this group of population are important cause of medical consultation and require prompt attention because of their impact on education, future work and quality of life. In the state of Uttarakhand, blindness has been reported in 29,107 cases, of which 5,371 cases are from age group 5 - 19 years.[1]

\section{MATERIALS AND METHODS}

The present study was done to determine the pattern of eye diseases and the socio-demographic factors responsible for the ocular morbidity among the patients aged 5 to 16 years from Kumaon region, who presented to the Department of Ophthalmology, Government Medical College, Haldwani, Uttarakhand, between October 2014 and October 2016.

A sample size of 400 was taken and a complete enumeration method was applied. A pre-designed proforma was used to document the patient particulars, history, examination and the diagnosis. Multiple ocular diseases were diagnosed by using different diagnostic test and criteria for individual diseases. Once the diagnosis was made by the attending ophthalmologist, the patient data and frequency of different ocular morbidities were documented. Socio-demographic factors responsible for ocular morbidity were studied by determining frequency of each morbidity in different age groups, gender and socioeconomic class.

\section{RESULTS}

In the present study, overall the disorders of ocular muscles, binocular movement, accommodation and refraction was the most common (37.25\%) cause of ocular morbidity followed by Disorders of conjunctiva (25.75\%), Congenital malformations of eye (7\%), Disorders of eyelid, Lacrimal system and orbit (6.50\%), Injury of eye and orbit (3\%), Superficial injury of eye (1.50\%), Disorders of sclera, cornea, iris and ciliary body (1\%), Disorders of choroid and retina $(0.75 \%)$ and Presence of functional implant (IOL) $(0.5 \%)$.

\section{CONCLUSION}

Most causes of ocular morbidity among the study group in this survey were avoidable, refractive error being the leading cause. Stable intervention programs targeting refractive errors, allergic conjunctivitis, infections of lid and adnexa and trauma may significantly decrease the burden of ocular morbidity in this region.

\section{KEYWORDS}

Eye Disease Pattern, Morbidity, Kumaon Region, Uttarakhand, Hilly Region, Indian State.

HOW TO CITE THIS ARTICLE: Kashyap A, Pandey S, Titiyal GS. Childhood ocular morbidity in Kumaon region- a tertiary hospital study. J. Evolution Med. Dent. Sci. 2017;6(18):1425-1429, DOI: 10.14260/Jemds/2017/312

\section{BACKGROUND}

India is home to 310 million children between the age of 5 16 years accounting for $25.6 \%$ of the country's population.[1] Eye diseases in this group of population are important cause of medical consultation and require prompt attention because of their impact on education, future work and quality of life. India has the largest blind population, more than any other country in the world. ${ }^{[2]}$

Financial or Other, Competing Interest: None.

Submission 19-01-2017, Peer Review 15-02-2017,

Acceptance 21-02-2017, Published 02-03-2017.

Corresponding Author:

Dr. Anshika Kashyap,

Room No. 18, Resident Hostel,

GMC Campus, Bareilly Road,

Haldwani, Nainital-263139.

Uttarakhand

E-mail: dranshikakashyap@gmail.com

DOI: $10.14260 /$ jemds $/ 2017 / 312$

\section{(c) $($ ) $९$}

Data on the prevalence and causes of childhood blindness and visual impairment in children are needed for planning and evaluating preventive and curative services including special education and low vision services. [3]

Of the total disability population of India, disability in seeing accounts for $18.8 \%$ of total, standing next only to disability in movement and hearing. India has a total population of 5 million people who have disability in seeing, of which 1.1 million are between the age group 5 - 19 years. In the state of Uttarakhand Blindness has been reported in 29,107 cases, of which 5,371 cases are from age group 5 - 19 years.[1]

Regional needs and conditions vary considerably and so are the diseases. Some diseases are more common in one part of the world than the other and the disease may differ in its manifestations in different areas due to geographical and climatic conditions. Very few studies have been done in Kumaon Region of Uttarakhand to study the epidemiology of ocular morbidity. This study is therefore designed to provide information about the pattern of childhood ocular morbidity 
in Kumaon Region and the consequences of ocular ill health. The information would help plan appropriate strategies, while striving to ensure the best possible ocular health status for a major proportion of the community.

\section{MATERIALS AND METHODS}

The present study was accomplished in the Department of Ophthalmology, Government Medical College, Haldwani, during the period of October 2014 - October 2016. Proper Ethical Clearance was obtained from Institutional Ethical Committee. All children were accompanied by their parent(s)/guardian(s), from whom written informed consent was taken for examination and for ocular/face photography. Data was collected after taking proper History and undertaking Clinical Examination.

It was a Hospital-Based, Cross-Sectional, Descriptive Study; 400 randomly selected patients aged 5 - 16 years were included in the study. All patients more than 16 years and less than 5 years of age were excluded. Children younger than 5 years were excluded, because of unavailability of the facilities for evaluation of preverbal children at our Institute. Also, children who came for followup, non-cooperative or whose parents did not give consent for the ongoing study were omitted from the study.

A complete enumeration method was applied. A predesigned Proforma was used to document the patient particulars, i.e. name, age (completed years), gender, religion, educational status, occupation of parents and family income. The socioeconomic status was determined using Kuppuswamy classification, 2014. ${ }^{[4,5]}$ A complete history was taken from the patients and their parents. Children were examined by ophthalmologists and refraction was done by optometrists. All patients had their vision tested on Snellen's or E chart. Those with poor vision $(<6 / 18)$ were tested with pinhole, then refraction was done by noncycloplegic/cycloplegic objective (Retinoscopy) and subjective refractions. Colour vision was assessed using Ishihara's chart. Adnexa, conjunctiva, cornea, anterior chamber, iris, pupils of all the participants were examined by torchlight and slit lamp. Fundus examination was done with direct ophthalmoscope and indirect ophthalmoscope when needed. Intraocular pressure was measured in both eyes using non-contact tonometer and applanation tonometer when needed. Extraocular movements, Hirschberg's test and cover-uncover test were done for detection of squint.

Multiple ocular diseases were diagnosed by using different diagnostic tests for individual diseases and by consideration of isolated diagnostic criteria of the disease. Once the diagnosis was made, the patient's data and frequency of different ocular morbidities were studied. Sociodemographic factors responsible for ocular morbidity were studied by determining frequency of each morbidity in different age groups, gender and socioeconomic class.

\section{Statistical Analysis}

The data was documented in an Excel $^{\mathrm{TM}}$ spreadsheet and analysed using SPSS Statistics ${ }^{\mathrm{TM}}$ software version 24 (IBM SPSS Inc., Chicago, IL, USA). Categorical variables were presented in number and percentage (\%). Qualitative variables were correlated using Chi-Square test/Fisher's exact test. A p value of $<0.05$ was considered statistically significant.

\section{RESULTS}

\section{Observation}

Of the 400 children, 236 (59.00\%) were males and 164 $(41.00 \%)$ females, i.e. a male-to-female ratio of 1.43:1. The mean age of presentation in our study was 10.695 years and the children were divided into 3 age groups: 5 - 9, 10 - 13 and 14 - 16 years. The consultation was more in the age group 5 9 years $(37.25 \%)$ and $10-13$ years $(37.00 \%)$. Table 1 illustrate gender distribution in different age groups from our study.

\begin{tabular}{|c|c|c|c|c|}
\hline \multicolumn{2}{|c|}{ Age (Years) } & \multicolumn{2}{|c|}{ Gender } & \multirow{2}{*}{ P value } \\
\cline { 3 - 4 } & F & M & \\
\hline \multirow{2}{*}{$\begin{array}{c}\text { Age } \\
\text { Group }\end{array}$} & $5-9$ & $58(35.37 \%)$ & $91(38.56 \%)$ & \multirow{2}{*}{0.289} \\
\cline { 2 - 4 } & $10-13$ & $57(34.76 \%)$ & $91(38.56 \%)$ & \\
\cline { 2 - 4 } & $14-16$ & $49(29.88 \%)$ & $54(22.88 \%)$ & \\
\hline
\end{tabular}

Table 1. Gender Distribution in Different Age Groups

Table 1: Values are presented as numbers (percentages). Analysed with Chi-square test. A p value of $<0.05$ was considered statistically significant.

According to census of India 2011, patients from Nainital and Udham Singh Nagar comprise $61.5 \%$ of total population of Kumaon region of Uttarakhand.[1] Maximum number of patients attending the OPD were from plains, i.e. Nainital (46.75\%) and Udham Singh Nagar (40.50\%), comprising a total of $87.25 \%$. Patients from hilly region comprised of only $12.75 \%$ of the total, which can be attributed to difficulty in conveyance and lack of awareness (Figure 1).

Patients from all socioeconomic backgrounds presented to the OPD, but patients with Class III status were predominant in our study with $35.25 \%$. Class II and Class IV represented 29.25 and $20.50 \%$ respectively. Class V and Class I represented $8 \%$ and $7 \%$ of the patients.

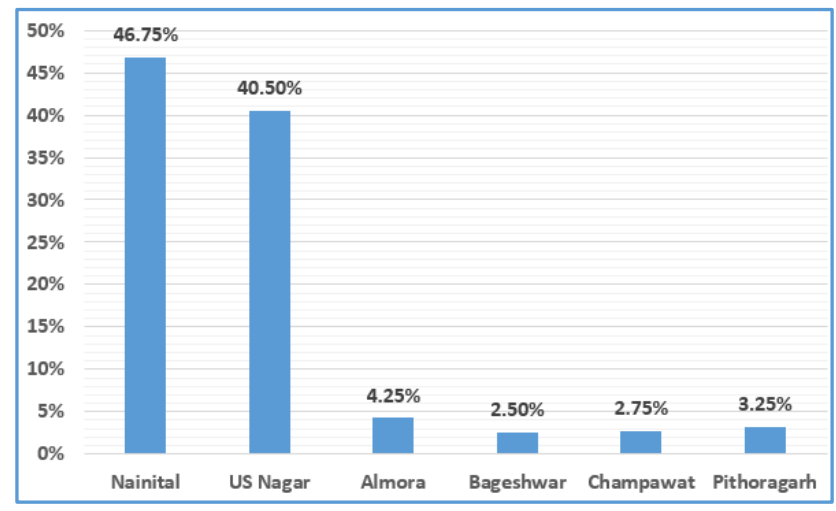

\section{Figure 1. Distribution of Patients from various Districts of Kumaon Region}

In the present study overall the disorders of ocular muscles, binocular movement, accommodation and refraction was the most common (37.25\%) followed by Disorders of Conjunctiva (25.75\%), Congenital malformations of eye (7\%), Disorders of eyelid, Lacrimal system and orbit (6.50\%), Injury of eye and orbit (3\%), Superficial injury of eye $(1.50 \%)$, Disorders of sclera, cornea, iris and ciliary body (1\%), Disorders of choroid and retina $(0.75 \%)$ and Presence of functional implant (IOL) (0.5\%). Table 2 and Figure 2 illustrate the distribution according to the type of morbidity. 


\begin{tabular}{|c|c|c|c|}
\hline Group & Ocular Morbidity & Frequency & Percentage \\
\hline A & $\begin{array}{l}\text { Disorders of eyelid, } \\
\text { lacrimal system } \\
\text { and orbit }\end{array}$ & 26 & $6.50 \%$ \\
\hline B & Disorders of conjunctiva & 103 & $25.75 \%$ \\
\hline $\mathrm{C}$ & $\begin{array}{l}\text { Disorders of sclera, } \\
\text { cornea, iris and ciliary } \\
\text { body }\end{array}$ & 4 & $1.00 \%$ \\
\hline $\mathrm{D}$ & $\begin{array}{l}\text { Disorders of choroid and } \\
\text { retina }\end{array}$ & 3 & $0.75 \%$ \\
\hline $\mathrm{E}$ & $\begin{array}{l}\text { Disorders of ocular } \\
\text { muscles, binocular } \\
\text { movement, } \\
\text { accommodation and } \\
\text { refraction }\end{array}$ & 149 & $37.25 \%$ \\
\hline $\mathrm{F}$ & $\begin{array}{l}\text { Visual disturbances and } \\
\text { blindness }\end{array}$ & 9 & $2.25 \%$ \\
\hline G & $\begin{array}{l}\text { Other disorders of eye } \\
\text { and adnexa }\end{array}$ & 1 & $0.25 \%$ \\
\hline $\mathrm{H}$ & $\begin{array}{c}\text { Congenital } \\
\text { malformations of eye }\end{array}$ & 28 & $7.00 \%$ \\
\hline $\mathrm{I}$ & Superficial injury of eye & 6 & $1.50 \%$ \\
\hline $\mathrm{J}$ & Injury of eye and orbit & 12 & $3.00 \%$ \\
\hline K & $\begin{array}{l}\text { General examination and } \\
\text { investigation of persons } \\
\text { without complaint and } \\
\text { reported diagnosis } \\
\end{array}$ & 57 & $14.25 \%$ \\
\hline $\mathrm{L}$ & $\begin{array}{c}\text { Presence of functional } \\
\text { implant-Intraocular lens }\end{array}$ & 2 & $0.50 \%$ \\
\hline \multicolumn{4}{|c|}{$\begin{array}{c}\text { Table 2. Values are Presented as Numbers and } \\
\text { Percentages }\end{array}$} \\
\hline
\end{tabular}

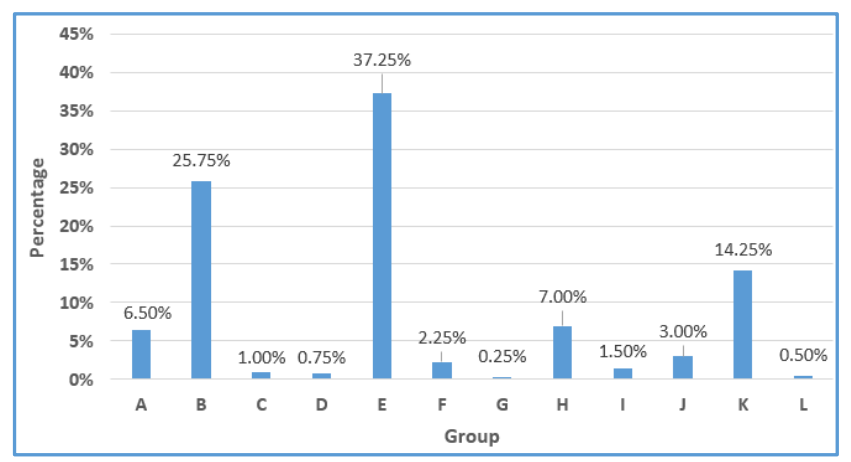

Figure 2. Distribution of Patients according to Type of Ocular Morbidity

\section{DISCUSSION}

Children have unique problems in terms of ocular morbidities, not only due to their inability to express their problems but also because of the potential to develop amblyopia. Although, most ocular lesions are preventable but due to ignorance and carelessness of being not attended to, they cause impairment of vision or even blindness. Childhood blindness is second only to cataract in terms of "blind years." Hence, strategies to manage paediatric ophthalmic disorders must be initiated as early as possible with interventions at all the three levels of primary, secondary and tertiary prevention. Various possible measures include optical, orthoptic, medical and surgical interventions.

Literature suggests different pattern of childhood ocular morbidity in different places and different study settings around the world. However, refractive errors and conjunctival diseases stay the two most common causes of ocular morbidity in children.

In the present study, overall the disorders of ocular muscles, binocular movement, accommodation and refraction was the most common (37.25\%) followed by disorders of conjunctiva (25.75\%), congenital malformations of eye (7\%), disorders of eyelid, lacrimal system and orbit (6.50\%), injury of eye and orbit (3\%), superficial injury of eye $(1.50 \%)$, disorders of sclera, cornea, iris and ciliary body (1\%), disorders of choroid and retina $(0.75 \%)$ and presence of functional implant (IOL) (0.5\%).

The findings are similar to the observations by Biswas et al, who found in their study that overall refractive errors were the most common ocular morbidity (23.67\%) followed by allergic conjunctivitis (17.23\%), infection of the eye and adnexa (15.13\%) and ocular trauma (12.74\%).[6] Also, Banayot et al reported that refractive errors were the most common ocular disorders seen (31.6\%) followed by conjunctival diseases (23.7\%) and strabismus and amblyopia (13.8\%).[7] Other studies reported involvement of conjunctiva as being the most common structure affected in ocular morbidity. Sethi et al[8] reported that conjunctiva was involved in $42.5 \%$. Refractive errors were present in $12.8 \%$ of the patients.

In the present study 149 (37.25\%) patients were suffering from disorders of ocular muscles, binocular movement, accommodation and refraction making it the most common ocular morbidity encountered in the study sample; $124(83.22 \%)$ patients had refractive error, $13(8.72 \%)$ had squint and 11 (7.38\%) convergence insufficiency. An overall male preponderance (87 males : 62 females) was seen. The diseases of ocular muscles, binocular movement, accommodation and refraction were noticed to be more prevalent in age group 5 - 9 years (51 patients) and $10-13$ years (55 patients); 55 patients belonged to the socioeconomic class III.

Refractive errors affect childhood development and without preschool or school eye screening for refractive errors, many children with refractive errors go unnoticed. Overall, 124 (31\%) patients were found to have refractive error in the study sample. Myopia was the most common refractive error with $64(16 \%)$ patients followed by hypermetropia (10.5\%) and astigmatism (4.5\%). Refractive errors showed a male preponderance. Myopia and astigmatism were most prevalent in age group 10 - 13 years, while hypermetropia was most prevalent in younger age group i.e. 5 - 9 years. Forty-four patients with refractive error belonged to socioeconomic class III, making it the most common class suffering from refractive error.

Literature reports refractive error as one of the most common ocular morbidity among children and myopia being the most common refractive error. Chakraborti et al[9] reported that refractive errors were present in 448 (9.15\%) children with myopia, hypermetropia and astigmatism. Refractive errors were found to be more in elderly age group (11 - 16 years). Salman and Associates ${ }^{[10]}$ described refractive errors accounted for $14.6 \%$ cases with a male preponderance of $67 \%$ and higher incidence was noted among older children 6 - 10 years constituting 66\%. A recent study by Banayot et al[7] showed that refractive errors were the most common disorders seen (31.6\%). 
In the present study, conjunctiva was involved in $25.75 \%$ patients making it the second most common morbidity in the study group. Within this group of conjunctival diseases, allergic conjunctivitis (75.73\%) was the most common disease followed by viral conjunctivitis (10.68\%) and mucopurulent conjunctivitis (9.71\%). Male preponderance was seen in all the three forms of conjunctivitis. Allergic conjunctivitis was more prevalent in age group 5 - 9 years, while the infective forms were more common in age group 10 - 13 years. There were $4(3.88 \%)$ cases of xerophthalmia showing signs of conjunctival xerosis X1A and Bitot's spots X1B (2 patients each). These patients also suffered from other nutritional deficiencies and improved on vitamin $A$ supplementation. We can say that vitamin A deficiency was not a major health problem in the study population. Salman et al reported that Allergic conjunctivitis was the most common disorder accounting for $27.0 \%$ of the cases with a male preponderance of $70.7 \%$ and higher incidence noted among older children 11 - 15 years. Infective conjunctivitis cases were 3.3\%.[10] Conjunctival diseases were the second most common disorder seen and represented $23.7 \%$ of cases in study by Banayot et al. Within this category, dry eye (Sicca) was more prominent among the 6 - 10 years' age group compared to other age groups $(\mathrm{p}<0.001) .{ }^{[7]}$

Congenital malformations of eye were the third most common ocular morbidity encountered in the study population. There were $28(7 \%)$ patients suffering from different congenital anomalies, of which cataract $(28.57 \%)$ was most common followed by congenital nasolacrimal duct obstruction (21.43\%) and congenital ptosis (14.29\%). There were $2(7.14 \%)$ patients each of congenital glaucoma, optic disc coloboma and punctal stenosis. We found 1 (3.57\%) patient each with blue sclera, iris coloboma, microphthalmos and Marfan's: congenitally displaced lens. Rahi and Colleagues concluded that disorders of the lens were seen in 162 children (12.3\%).[11] Rogers et al found congenital cataract as the leading cause of surgically correctable blindness in most developing countries.[12]

In a recent study, Garg et al[13] also reported the most common congenital disorder causing preventable blindness as congenital cataract seen in $19 \%$ patients followed by congenital ptosis in $6 \%$ and congenital strabismus in $3.5 \%$ patients. Congenital causes of irreversible blindness found were developmental anomalies of eyeball/cornea, iris and lens, retinal dystrophies and optic nerve anomalies (23\%). These included microcornea (2\%), microcornea with iris coloboma $(1 \%)$, sclerocornea $(0.5 \%)$, iris coloboma $(7 \%)$, aniridia (6.5\%), ectopia lentis (4\%), coloboma of lens $(1 \%)$, anophthalmos (0.5\%) and microphthalmos (1.5\%). Retinal disorders were seen in $25.5 \%$ patients. Retinitis pigmentosa was present in 34 patients $(17 \%)$. In the present study, the second most frequent congenital disorder seen in the study group was CNLDO (Congenital Nasolacrimal Duct Obstruction) occurring in $21.43 \%$ cases. Salman M S described that NLD obstruction contributed to $5.2 \%$ of cases, males (34\%) were predominantly affected and higher incidence noted among those less than 5 years $64 \% .{ }^{[10]}$ Sethi and coworkers denoted that nasolacrimal duct was involved in $5.4 \%$ cases. ${ }^{[8]}$

Congenital anomalies are found to be the common cause of blindness in childhood. In common with other developing countries, a large proportion of the childhood blindness in
India is avoidable. It would be useful to document the causes of childhood blindness to allow early action against emerging avoidable causes. This study advocates the need of instituting screening programs at the maternity centres before babies are discharged for early detection of congenital eye diseases and treatment of those that can cause preventable blindness and the need for premarital counseling to avoid congenital ophthalmic disorders.

In our OPD we found 26 patients (6.50\%) suffering from disorders of eyelid, lacrimal system and orbit, making it the fourth most common presentation. There were 8 cases $(30.77 \%)$ of blepharitis, 5 females and 3 males. There were 7 cases of Chalazion (26.92\%), 5 females and 2 males; 6 $(23.08 \%)$ children presented with stye, 5 females and 1 male. There were $3(11.54 \%)$ cases of chronic dacryocystitis and 2 $(7.69 \%)$ cases of orbital cellulitis, all males. In a recent description by Banayot et al,[7] lid diseases were the fourth most common presentation representing $9.2 \%$ of cases. Lacrimal diseases were sixth most common presentation in that study and represented $6.1 \%$ of cases. Salman and Colleagues also reported blepharitis in $21(2.48 \%)$ cases, stye in $4(0.47 \%)$, dacryocystitis in $8(0.95 \%)$, orbital cellulitis in 6 $(0.7 \%)$ and preseptal cellulitis in 5 (0.59\%).[10] Though simple to treat, disorders of lids make a major proportion of childhood ocular morbidity presenting to eye care professionals. We through this study advocate early consultation and prompt treatment to avoid complications.

Only 6 male patients (1.5\%) with black eye S00 presented to the OPD, though there is a larger frequency of the same in emergency department. The most common aetiology of black eye in our study was found to be head injury by fall from height. There was no female patient with black eye. A total of $12(3 \%)$ patients presented with injury of eye and orbit S05. Of which, 8 patients (66.67\%) had closed globe injury, traumatic cataract and traumatic hyphema being common presentations. Like several other studies, closed globe injury was most common injury noted in the present study and[14,15] a male preponderance was seen. Saxena and coworkers demonstrated that closed globe injuries accounted for $42.2 \%$ injuries, open globe for $53.9 \%$ and $3.9 \%$ were chemical injuries.[16] Penetrating trauma, mostly presenting with corneal tear and uveal tissue prolapse was seen in 4 cases.

The frequency of eye injuries among children is remarkably high and a major cause of unilateral noncongenital visual impairment and blindness worldwide.[17,18] The major cause of ocular trauma in children includes unsupervised play, use of dangerous objects and unnecessary risks at play are equally common in developed and developing countries. Incidence of ocular trauma is significantly higher in boys in all countries.[18]

In the present study, we found 2 male patients with uveitis both of which were associated with juvenile rheumatoid arthritis, 1 male patient with anterior staphyloma and 1 female patient with corneal opacity as a complication of trachoma.

There were three cases of retinitis pigmentosa $(0.75 \%)$ in our study, 2 males and 1 female. Banayot R G et al reported that retina and vitreous disorders represented $1.6 \%(n=14)$ of cases in their study.[7] The picture of retinal disorders varies from that of other studies where retinoblastoma is frequently reported. The variation may be due to exclusion of children younger than 5 years from the study. Two children 
presented with pseudophakia, both were males belonging to socioeconomic class II. One was operated for congenital cataract and the other for traumatic cataract many years back. There was one male patient $0.25 \%$ with congenital nystagmus.

In our OPD, we found 57 (14.27\%) patients referred from Paediatric Department to rule out refractive errors. These children did not have any ocular complaints, but presented to paediatric OPD with complaints of headache. On ophthalmological evaluation, we did not find any abnormality in vision or any other ocular disease. There were also some children referred from schools for screening. None of these children had any ocular complaints and the ophthalmological examination was normal.

\section{CONCLUSION}

In conclusion, most causes of visual impairment among the study group in this survey were avoidable, refractive error being the leading cause. Stable intervention programs targeting refractive errors, allergic conjunctivitis, infections of lid and adnexa and trauma may significantly decrease the burden of visual impairment in the area. Health education that raise awareness about preventable and curable eye diseases and the benefits of personal and environmental sanitation as well as early presentation of children to eye care centres for the treatment of eye disorders are mandatory.

\section{REFERENCES}

[1] Census of India, Administrative Atlas of India, Office of the Registrar General \& Census Commissioner, New Delhi, 2011.

[2] Sinha K. India has largest blind population. http://timesofindia.indiatimes.com/india/India-haslargest-blind-population/articleshow/2447603.cms 2016.

[3] Gilbert CE, Anderton L, Dandona L, et al. Prevalence of visual impairment in children: a review of available data. Ophthalmic Epidemiol 1999;6(1):73-82.

[4] Oberoi SS. Updating income ranges for Kuppuswamy's socio-economic status scale for the year 2014. Indian J of Public Health 2015;59(2):156-7.

[5] Gururaj, Maheshwaran. Kuppuswamy's Socio economic status scale - a revision of income parameter for 2014. International Journal of Recent Trends in Science and Technology 2014;11(1):01-2.
[6] Biswas J, Saha I, Das D, et al. Ocular morbidity among children at a tertiary eye care hospital in Kolkata, West Bengal. Indian J Public Health 2012;56(4):293-6.

[7] Banayot RG. A retrospective analysis of eye conditions among children attending St. John eye hospital, Hebron, Palestine. BMC Res Notes 2016;9(1):202.

[8] Sethi S, Sethi. Pattern of common eye disease in children attending outpatient eye department in khyber teaching hospital. J Med Sci 2008;16(2):99101.

[9] Chakraborti C, Mondal M, Choudhury KP, et al. Clinical profile of paediatric ocular morbidity in a tertiary eye care centre in West Bengal. Bengal Ophthal J 2012;303.

[10] Salman MS. Pediatric eye diseases among children attending outpatient eye department of tikrit teaching hospital. Tikrit Journal of Pharmaceutical Sciences 2010:7(1).

[11] Rahi JS, Sripathi S, Gilbert CE, et al. Childhood blindness in India: causes in 1318 blind school students in nine states. Eye 1995;9(Pt 5):545-50.

[12] Rogers NK, Strachan IM. Pierre Robin anomalad, maculopathy and autolytic cataract. J Pediatr Ophthalmol Strabismus 1995;32(6):391-2.

[13] Garg P, Qayum S, Dhingra P, et al. Congenital ocular deformities- leading cause of childhood blindness a clinical profile study. Indian Journal of Clinical and Experimental Ophthalmology 2016;2(1):22-7.

[14] Onakpoya OH, Adeoye AO. Childhood eye diseases in southwestern Nigeria: a tertiary hospital study. Clinics 2009;64(10):947-51.

[15] Alhaski M, Almaaita J. Retrospective analysis of pediatric ocular trauma at Prince Ali hospital. Middle East J Fam Med 2007; 5:45.

[16] Saxena R, Sinha R, Purohit A, et al. Pattern of pediatric ocular trauma in India. Indian $\mathrm{J}$ Pediatr 2002;69(10):863-7.

[17] Niiranen M, Raivio I. Eye injuries in children. Br J Ophthalmol 1981;65(6):436-8.

[18] Rapoport I, Romem M, Kinek M, et al. Eye injuries in children in Israel. A nationwide collaborative study. Arch Ophthalmol 1990;108(3):376-9. 